\title{
Experiência e racionalidade estética no trabalho docente
}

\author{
Experience and aesthetic rationality in teaching work ${ }^{1}$
}

\begin{abstract}
Maurício Inácio dos Santos ${ }^{2}$
Carlos Betlinski ${ }^{3}$

\section{Resumo}

Compreender o trabalho docente como experiência, incorporar a racionalidade estética e o cuidado de si tornam-se condições para a sua valorização. $O$ enfraquecimento e a precarização das atividades educativas na sociedade contemporânea tem provocado angústia e desencanto em muitos professores e, diante desta realidade elabora-se o seguinte problema para direcionar nossa discussão: Qual é o lugar da experiência estética no contexto do trabalho docente? Como objetivos desta incursão teórica problematiza-se as condições concretas das atividades educativas na sociedade neoliberal, pois impedem a experiência e a construção de sentido para os sujeitos dessas atividades e, propõe-se a racionalidade estética e o cuidado de si como fundamentos do ofício docente conferindo-lhe um sentido artístico. O caminho de construção do texto percorreu o pensamento de Walter Benjamin e Theodor Adorno, e uma aproximação das ideias de Michael Foucault com esses teóricos, considerando os conceitos de experiência, racionalidade estética, cuidado de si e estética da existência. Como resultados da discussão evidenciou-se que ao resgatar a racionalidade estética em seu trabalho, o docente pode tonificar sua atuação profissional, mesmo diante de uma tendência histórica da sociedade capitalista de desvalorização do professor e imposição de uma racionalidade instrumental como forma de controle que ele mesmo acaba reproduzindo em seu fazer pedagógico. O cuidado de si cria espaço para pensar a necessidade do docente cultivar práticas e exercícios corporais e mentais que o levem a criar um estilo particular de ser superando os limites do pensamento e das práticas burocratizadas neoliberais, abrindo possibilidades de construção de um ofício assentado na experiência estética.
\end{abstract}

Palavras-Chave: Trabalho docente; Experiência; Racionalidade Estética; Cuidado de si; Estética da existência.

\footnotetext{
Abstract

Understanding teaching work as an experience, incorporate aesthetic rationality and self-care become conditions for its valorization. The weakening and precariousness of educational activities in contemporary society has caused anguish and disenchantment in many teachers and, given the current scenario, the following problem is elaborated to direct our discussion: What is the place of aesthetic experience in the context of teaching work? As objectives of

${ }^{1}$ Agência de fomento: FAPEMIG - APQ 02218-18 “O cinema novo como experiência inovadora da formação cultural docente".

${ }^{2}$ Mestre em Educação pela Universidade Federal de Lavras (UFLA). Graduado em História e Pedagogia. Professor da Fundação Presidente Antônio Carlos (Unipac). Lambari/MG - Brasil

E-mail: prof.mauricio.i.s@hotmail.com

3 Doutor em Educação pela PUC/SP. Professor do Programa de Pós-Graduação em Educação da UFLA. Lavras/MG - Brasil. E-mail: carlosbetlinski@ufla.br
}

Revista Devir Educação, Lavras, vol.4, n.2, p.343-372 jul./dez., 2020. 
this theoretical incursion, the concrete conditions of educational activities in neoliberal society are questioned, as they impede the experience and the construction of meaning for the subjects of these activities, and aesthetic rationality and self-care are proposed as foundations of the teaching profession. giving it an artistic sense. The construction of the text followed the thinking of Walter Benjamin and Theodor Adorno, and an approximation of Michael de Foucault's ideas with these theorists, considering the concepts of experience, aesthetic rationality, self-care and aesthetics of existence. As a result of the discussion, it became evident that when rescuing aesthetic rationality in his work, the teacher can tone his professional performance, even in the face of a historical tendency in the capitalist society of devaluation of the teacher and the imposition of an instrumental rationality as a form of control that he himself ends up reproducing in his pedagogical practice. Self-care creates space to think about the need for the teacher to cultivate body and mental practices and exercises that lead him to create a particular style of being overcoming the limits of thinking and the neoliberal bureaucratic practices, opening up possibilities for building a profession based on aesthetics experiences.

Keywords: Teaching work; Experience; Aesthetic Rationality; Self-care; Aesthetics of existence;

\section{Introdução}

Analisar o trabalho docente na perspectiva da experiência e da racionalidade estética pode figurar como um contrassenso, e há quem diga que essa forma de direcionar as atividades pedagógicas está fora de contexto diante de uma realidade que demanda por profissionais com perfil empreendedor ou que faça uma adesão aos ditames da racionalidade neoliberal.

No entanto, este perfil empreendedor, acaba criando e reforçando a imagem de um professor estereotipado e a partir da concepção da racionalidade neoliberal, o docente acaba se convertendo em um planejador e executor burocrático de tarefas, controlador da ordem para que haja disciplina e eficiência dos "produtos educativos" ao rigor da ideia de qualidade. Controlado e robotizado, o trabalho docente torna-se descaracterizado na sua essência de formação da pessoa e somado a precarização das condições de suas atividades acaba provocando desencantos do professor com seu trabalho. O desânimo, o enfraquecimento de si, a acomodação e reprodução dessa racionalidade dentro do contexto de suas atividades educativas.

Partindo da tese que a racionalidade instrumental, a tecnificação, a burocratização dos processos e o controle externo do trabalho docente na sociedade neoliberal impede a experiência e exclui a racionalidade estética na condução do trabalho ou da prática 
pedagógica e, mediante a intuição de que é possível falar de estética no trabalho docente, propõe-se o seguinte problema para esta incursão teórica: Qual é o lugar da experiência estética no contexto do trabalho docente?

Como objetivos para este ensaio propõe-se problematizar as condições de precarização do trabalho vivenciadas pelos docentes na contemporaneidade por meio dos conceitos de experiência e racionalidade estética na perspectiva do pensamento de Walter Benjamin e Theodor Adorno, e, estabelecer uma relação destes conceitos com o trabalho docente na sociedade neoliberal, e, propor a racionalidade estética e o cuidado de si como fundamentos da atividade docente, conferindo-lhe um sentido de artístico como forma de potencializar o ofício pedagógico.

Para direcionar nossas análises percorre-se um caminho de aproximação do pensamento de Foucault (Hermenêutica do sujeito) quando este pensador recorreu ao conceito de cuidado de si para abordar as dimensões ética e estética da constituição subjetiva do sujeito. Em sua estética da existência que figura como a criação de um estilo, de um modo de viver e de sua ética da liberdade que inspira a escolha de valores que guiarão a conduta moral do sujeito há evidentemente uma preocupação, inspirado nas escolas filosóficas grecoromanas, com um sentido maior da existência. Poderíamos pensar sobre a possiblidade de vincular esse modo de pensar que une estética e ética ao modo de ser professor? O ocupar-se consigo mesmo, o cultivar-se, o uso de técnicas e procedimentos, a escolha de valores éticos, estéticos, políticos e a possiblidade de criação ou construção de si como uma obra de arte poderia ser aplicado para pensar a profissão docente?

O cuidado de si abre espaço para pensar a necessidade do docente cultivar práticas e exercícios que podem fortalecer seu interior, sua mente, ao criar um estilo particular de ser que supera os limites impostos pela racionalidade instrumental, fundamentando seu ofício e sua existência numa racionalidade estética diferente daquela imposta pelos ditames da sociedade neoliberal e neste ponto, por caminhos diferentes, Benjamin, Adorno e Foucault podem trazer contribuições para dialogar com nosso objeto de análise.

\section{Breve caracterização do trabalho docente segundo as prerrogativas da racionalidade neoliberal.}

$\mathrm{Na}$ medida em que o neoliberalismo monopolista venceu todas as batalhas $\mathrm{e}$ resistências, sua ideologia dominadora fincou raízes dentro da escola, como instituição de 
base da formação da sociedade e de construção do indivíduo, por meio de seus diversos instrumentos de dominação e de influência, sobretudo da razão instrumental, em forma de racionalidade técnica e da indústria cultural que pode ser apontada como responsável por prejudicar a capacidade humana de agir com autonomia, pois pelos seus mecanismos de manipulação, a consciência humana foi dominada pela comercialização e banalização dos bens culturais.

Neste ponto, consciência e experiência, emoção e sensibilidade constituidoras do trabalho docente, são ofuscadas ou substituídas por metas, quantificação, padronização, rigor técnico, burocracia, repetição, punição e controle de qualidade por meio de resultados quantitativos, abafando a experiência formativa ética e estética, antecipando no próprio cotidiano escolar, como chão das primeiras experiências sociais no sentido amplo, a adaptação, a semicultura, a falsa ideia de democratização da cultura e de igualdade de acesso aos bens culturais e principalmente, de forma reprodutivista a escola incorpora a lógica da fábrica, como lugar de alienação e experiências anestética.

Buck-Morss nos permite pensar nessa analogia do trabalho docente nas escolas no sentido negativo, com o trabalho nas fábricas,

os trabalhadores aprendem a coordenar gestos com o movimento incessante
de um autômato. Independentemente da vontade do trabalhador, o artigo em
elaboração chega sua esfera de ação e dela se afasta com igual arbitrariedade
A extrapolação aqui deve ser entendida como uma categoria cognitiva, e não
econômica: o sistema fabril, danificando cada um dos sentidos humanos,
paralisa a imaginação do trabalhador. Seu trabalho é isolado da experiência;
a memória é substituída pela resposta condicionada, pelo aprendizado por
treinamento mecânico, pela destreza repetitiva: a prática de nada vale
(BUCK-MORSS, 1996, p. 23).

Sob o imperativo da racionalidade técnica, o trabalho docente tende a vivenciar um processo que reforça a submissão, o servilismo, a acriticidade, a falta de criatividade, de autonomia do pensamento, o reprodutivismo em meio a indisciplina, o desinteresse e falta de perspectiva para os horizontes do saber, quase sempre escravizado pelo discurso meritocrático e de poder sobre os alunos como forma de ascensão escolar e social. Sob a influência da racionalidade técnica, o trabalho docente torna-se apenas o executor de programas curriculares, metas e planos de ensino formulados por especialistas. Com isso, tende a ver o seu trabalho reduzido às aulas rotineiras, aplicação de exames, controle da disciplina, zelo e pontualidade com escrituração exata da burocracia por meio dos diários, planos de aula, planejamentos, fichas de acompanhamento, provas, atividades, exercícios, deveres, 
treinamentos, projetos educativos e temáticos a serem executados e tantas outras atividades burocráticas que permeiam o cotidiano escolar.

O trabalho docente, na lógica da racionalidade técnica e da indústria cultural acaba por seguir padrões, ignorar as diferenças subjetivas, o histórico de vida de cada aluno, suas trajetórias humanas e escolares, o que se passa no seu interior, suas reações corporais e acaba se regendo pelo autoritarismo onde não há espaço para o sorriso, a brincadeira, para a pergunta, o aprender com prazer. Diante deste contexto, o trabalho docente se apresenta em muitas situações, como um lugar pouco empolgante, símbolo muitas vezes da insatisfação e frustração, tanto de alunos como de professores, em muitos casos, espelhos da violência verbal e física da sociedade.

A ideia de nota, conceito, aprovação, reprovação, no limite da "régua" da racionalidade técnica, tende a induzir e reproduzir pelo trabalho docente a situação de mercantilização da sociedade administrada. Reproduzindo os ditames da indústria cultural, não raramente o trabalho docente é para agir, falar, escrever e pensar igual. Como uma prisão, tudo é controlado, estes são submetidos à tortura do repetir, copiar, decorar. Anula-se seu encanto, a autonomia criadora, falam frases feitas, decoram conceitos que não condizem com o seu horizonte existencial, tem medo de ousar. Tudo é passado pelo crivo do "certo" e “errado", “aprovação" e "reprovação", "punição". Isso inibe, amedronta, aprisiona, empobrece o sentido de experiência e estética que precisa marcar o trabalho docente. (RAMOS-DE-OLIVEIRA, 2002, p. 20)

Refletindo sobre a questão da hegemonia racionalidade técnica presente no trabalho docente, um sério questionamento sobre o que ainda reina nos cotidianos escolares pode ser feito, pois,

enquanto o ritmo do cotidiano escolar for ditado pelos esquemas tayloristas de horários e calendários feitos na diretoria ou secretaria ou ditado pelas aulas sequenciais e ordenação dos conteúdos páginas após páginas dos livros didáticos, o poder pedagógico estará a muitos quilômetros de distância dos atores. Para professor e aluno, a coisa mais importante continuará sendo o salário e a nota no fim do mês, e a sirene no fim da aula. Ufa! O fim semana está chegando! Continuará perpetuando, o pacto da mediocridade, o professor finge que ensina e os alunos fingem que aprendem e quem mandará na sala de aula é o horário e o calendário, as provas que nada provam, e as notas e diplomas que encerram um ciclo de faz de contas (MONLEVADE, 2000, p. 45-46).

Neste sentido, o trabalho docente que sucumbe a perspectiva taylorista e fordista e se volta para os ditames da racionalidade técnica e da indústria cultual vê-se desfocado e 
empobrecido na essência do processo que o move, a saber a experiência do ensinar e do aprender, o sentir, pensar e agir. A racionalidade neoliberal consagra as ideias de razão, técnica e eficiência acima de uma formação geral do ser humano, condicionando e influenciando os comportamentos dos indivíduos que tendem a pensar e agir segundo a sua lógica de massificação, controle de suas atitudes e decisões. Nessa lógica, evidencia-se uma separação entre o sentir, pensar e agir no trabalho docente, onde há uma tendência crescente na valorização de uma prática centrada na questão do conteúdo, das habilidades e competências como capacitação para o mercado de trabalho e um exaustivo processo de atividades burocráticas regulamentadas e medidas por notas, conceitos, avaliação de desempenho, ofuscando a questão do sentir como uma experiência que fundamenta a existência, portanto o pensar e agir.

Pode-se afirmar que do encanto formativo que permeia o processo do trabalho docente, segue o desencanto, cansaço, frustração e estresse, pois, esta realidade imposta pela racionalidade neoliberal gera uma apatia nos docentes, aceitação de uma realidade que parece ser incapaz de ser mudada, uma vez que nas escolas, as grades, as trancas, os portões de ferro, tudo parece proteger de uma violência de fora, mas que já está lá dentro, entre práticas e representações simbólicas: muitos afazeres burocráticos, vozes, gritos, indisciplinas, avaliações, baixos salários, horários exaustivos, ritmos acelerados, entre outros. Todos esses fatores tornam superficiais as relações entre professores e alunos que acabam por não ter mais tempo para fazer experiências, que necessitam ser narradas e compartilhadas (RAMOS-DEOLIVEIRA, 2007).

Neste ponto, é interessante perceber que a impossibilidade de narrar e ter experiências do cotidiano, não foi uma exclusividade dos soldados que voltaram da grande guerra, emudecidos, dos campos de batalha como lembrava Benjamin (1986), mas é a imagem do próprio cotidiano escolar, ao ser possível constatar que milhares de professores e alunos deixam a escola após uma longa jornada de trabalho emudecidos e sem nada a contar, muitos nem sequer desejam contar o que se passou, as experiências vividas. Este emudecimento se agrava ainda mais, quando este cotidiano escolar é marcado por situações adversas. O emudecimento é resultado da não experiência ou de vivências e experiências traumáticas.

No neoliberalismo, em nome da racionalidade técnica, nossas ações moldaram-se e incorporaram-se a essa lógica, pois, o ser humano parece fundamentar o processo produtivo que o constitui e não consegue se relacionar de outra forma com o mundo a sua volta, 
incluindo o seu semelhante. O ritmo frenético da técnica que consagrou a ideia de que tudo tem que ser produzido para a troca cria uma cultura do descarte. Na sociedade da produção industrial tudo deve ser consumido brevemente, sem diferenciação para que possa ser substituído por outro recurso ou produto a ser incorporado, obrigando a troca rápida, o consumidor livra-se do "antigo" e vai se adaptando ao "novo" lançamento, quase sempre imagem e semelhança do anterior.

Deste modo, se de um lado há uma perda do sentido de experiência, por outro há uma perda danificadora da existência humana que constitui o enfraquecimento da sensibilidade, base da experiência estética. Induzida pela racionalidade instrumental e focada na questão pragmática, por meio de um ensino conteudista onde prevalece o intelecto sobre as emoções, regido pela sequência lógica, ordeira, cronológica, sob controle de exames e avaliações a educação e o trabalho docente perde ou mesmo nega a possibilidade de uma experiência estética ao deixar de lado a questão do afeto, da imaginação, da contemplação do belo, da criação, entendidos aqui como toda a experiência que permite cada sujeito, ao seu tempo e modo experimentar o sentimento da emoção, da alegria, do sofrimento, do êxtase, do encantamento, da reflexão que faz pensar a vida, da resiliência, experiências que podem ser vividas pela arte em suas diversas expressões, seja sonora ou imagética ou mesmo nas situações cotidianas da sala de aula e que são capazes de reconstruir em cada um a humanidade sucateada pelo capital e o fetiche da mercadoria. Na concepção neoliberal, as instituições escolares devem funcionar como empresas produtoras de serviços educacionais e o trabalho docente ser reduzido a um "prestador" de serviços dos produtos educacionais padronizados.

\section{Experiência e racionalidade estética no trabalho docente: interpretações a partir de Walter Benjamin e Theodor Adorno}

A definição do que venha a ser experiência nos coloca diante de um conceito polissêmico que vai do senso comum a definições mais sistematizadas, abrangendo diversas áreas do conhecimento. A palavra experiência vem do latim experiri, deve ser entendido como provar, experimentar. Segundo Larrosa (2002, p. 25), “a existência é em primeiro lugar um encontro, uma relação com algo que se experimenta, que se prova". Ainda, segundo o mesmo autor, pelo seu radical periri evoca a ideia de perigo; e se tomado como referência o grego, remeteria a ideia de travessia, o percorrido, a passagem, até mesmo pirata, o que nos 
colocaria frente a ideia de que a experiência, supõe a exposição, o atravessar espaços indeterminados e perigosos, pondo-se a prova, em busca de oportunidade e ocasião, a exemplos dos piratas. E conclui Larrosa (2002, p. 26), "a experiência seria a passagem da existência, a passagem de um ser que não tem essência ou razão ou fundamento, mas que simplesmente "ex-iste" de uma forma sempre singular, finita, imanente, contingente".

No campo da filosofia, a experiência está relacionada a qualquer conhecimento obtido por meio dos sentidos, em outras palavras, a apreensão sensível da realidade externa de forma empírica, isto é, sem a necessidade de comprovação e de teorias e métodos científicos. Ainda, considerando Larrosa (2002, p. 2), na perspectiva filosófica, "a experiência é o que nos passa, o que nos acontece, o que nos toca. Não o que se passa, não o que acontece, ou o que toca". O que nos passa, considerando que o sujeito da experiência é sempre um território de passagem, mas que devido a sensibilidade, o que nos acontece tem poder de afetar, deixar marcas, vestígios e efeitos. Que nos toca, como lugar que recebe as coisas e que ao receber, lhe dá lugar (p. 21).

Benjamin (1986) apresenta inquietações teóricas em relação ao pensamento de Kant, que defendia como experiência somente aquilo pudesse ser comprovado cientificamente. Procurou defender um novo conceito de experiência que superasse a limitação, segundo sua visão, do conceito kantiano, visto por ele, como insuficiente e reducionista para compreender e explicar as infinitas possibilidades da experiência moderna. Benjamim parte de críticas ao conceito que Kant tinha sobre experiência, como forma de ampliar este conceito de modo que pudesse ser aplicado a uma totalidade de situações e tudo o que faz parte do existir humano.

Segundo Benjamin (1986), Kant e os iluministas, influenciados por uma perspectiva mecanicista dominada pela ciência e pelas inovações físicas e matemáticas incorreram em uma concepção restrita de experiência entendida pelo autor como de nível baixo, dentro do período iluminista.

Jarek (2014), corrobora com essa afirmação benjaminiana ao demonstrar que esse completo enquadramento da vida na questão racional, focado no ordenamento e classificação reflete os sintomas de angústia do sujeito burguês sobre o qual se fundou o Iluminismo, angústia que resulta da limitação da experiência pela razão. Olgária Matos (1993), em sintonia com as afirmações anteriores, acrescenta que Benjamin, propunha outras formas de experiência, como a experiência religiosa, cultural, estética, histórica, entre outras como enfrentamento ao individualismo racionalista imposto por uma experiência reducionista, 
matematicista e mecanicista oriunda do próprio Iluminismo.

A intuição benjaminiana parte do desejo de elaboração de um conceito de experiência que possa ser superior a percepção kantiana. O autor coloca em questão a possibilidade da busca da certeza de uma experiência que permaneça, tenha dimensão atemporal e duradoura, em contraposição a uma experiência temporal e passageira. O conceito de experiência em Benjamin toma como base a expressão Erfahrung, tendo como oposto o conceito de vivência, a partir da expressão Erlebnis. Ao retomar o estudo do conceito de Erlebnis em Benjamin temos uma referência ao alemão Erleben, que nos remete a ideia do estar vivo enquanto um fato acontece. Vivência porque se testemunha o momento, no sentido de provisoriedade, fugacidade, como algo isolado e segundo Konder (1998), neste sentido, uma vivência apegada as exigências de uma existência prática, ligada a cotidianidade, permeada pela pressa e pelos efeitos imediatos de algo que precisa ser assimilado, pois senão pode passar e cair no esquecimento. Assim, continua Konder, emerge um tipo de homem e humanidade que vive o presente sem laços com o passado, entorpecido pelos apelos da sociedade consumista, desorientado e sem norte, mediante uma velocidade que caracteriza todas as suas ações e vivências, induzido ao esquecimento, sem espaço para a memória.

A experiência para Benjamin (1986) é o conhecimento que se obtém através daquilo que se acumula no indivíduo, que se desdobra como permanência. Daí a expressão Erfahrung, derivado do alemão Fahren, que remete a ideia de viagem que supõe um tempo capaz de dar sedimento as coisas ou processos e modos de vida individual e coletiva que se alimentam pela partilha, intimidade, vínculos e que se estabelecem pela força da memória.

Benjamin refere-se ao apequenamento desta experiência na modernidade, que segundo ele é uma experiência diminuída, retrato de indivíduos que não se pautam mais no coletivo, na tradição, na memória, na comunidade. A técnica fez perder o sentido de tudo, enfraquecendo e esfacelando as experiências (BENJAMIN, 1986).

Em "Experiência e Pobreza" de 1933, Benjamin, identifica vários campos como a arte, a cultura, a história, entre outros, onde se estabeleceu um empobrecimento da experiência na modernidade. A imagem de um ancião à beira da morte comunicando aos seus filhos o seu tesouro, nos remete a lição de transmissão de experiência, que conferiria autoridade aos mais velhos, que a consolidava e perpetuava por meio da história, da narrativa que sedimentava o ver, viver, contar, ouvir e transmitir, engendrando no tempo a memória, como força que sedimenta uma experiência (BENJAMIN, 1986). 
No entanto, Benjamim, alerta para o processo de enfraquecimento da experiência com questionamentos provocadores:

O que foi feito de tudo isso? Quem ainda encontra pessoas que saibam contar histórias como elas devem ser contadas? Que moribundos dizem hoje palavras tão duráveis que possam ser transmitidas como um anel, de geração em geração? Quem é ajudado, hoje, por um provérbio oportuno? Quem tentará, sequer, lidar com a juventude invocando sua experiência? (BENJAMIN, 1986, p. 114).

Para Benjamin, a experiência se constituía em uma forma comunitária de organizar e viver a vida, marcada pelo rito de passagem e transmissão, pelos gestos, ações, sentimentos, memória, partilha, onde o individual se conectava com uma rede de significados coletivos que permitia um intercâmbio de experiências que eram construídas e que reforçava a identidade de um grupo, por meio da vivência concreta de intimidade e vínculos afetivos. Em Benjamin (1986, p. 115), a experiência é o elo que nos vincula ao passado em seu aspecto social, histórico e cultural, no sentido material e imaterial. Porém, a humanidade está apartada desta experiência, vivendo um estado de empobrecimento que não é individual, mas diz respeito a humanidade como um todo. Com o empobrecimento da experiência, essa perde o seu significado, abrindo espaço para a barbárie. É justamente num contexto de muitos acontecimentos violentos que culminaram num estado de barbárie que Benjamin percebe este processo de empobrecimento: supremacia da técnica e do progresso; grandes guerras; crise econômica mundial; ascensão do nazismo e do fascismo.

Benjamin nos faz pensar na dimensão da experiência empobrecida ao testemunhar e refletir sobre a condição do pós-guerra e da crise econômica nos primeiros anos do século XX. Sofrimento, morte, horror, fome e miséria, entre outros, provocaram o emudecimento e a pauperização da experiência.

Na época já se podia notar que os combatentes tinham voltado silenciosos do campo de batalha. Mais pobres em experiências comunicáveis, e não mais ricos (...) Porque nunca houve experiências mais radicalmente desmoralizadoras que a experiência estratégica pela guerra de trincheiras, a experiência econômica pela inflação, a experiência do corpo pela fome, a experiência moral pelos governantes (BENJAMIN, 1986, p. 114-115).

Para além das guerras e seus horrores, Benjamin, percebe na questão do progresso tecnológico moderno, também uma forma de miséria e empobrecimento, ao lançar o homem numa procura frenética pela questão da espiritualização:

Uma nova forma de miséria surgiu com esse monstruoso desenvolvimento

Revista Devir Educação, Lavras, vol.4, n.2, p.343-372 jul./dez., 2020. 
da técnica, sobrepondo-se ao homem. A angustiante riqueza de ideias que se difundiu sobre as pessoas com a renovação da astrologia, da ioga, da Christian Science, da quiromancia, do vegetarismo, da gnose, da escolástica e do espiritualismo" (BENJAMIN, 1986, p.115).

Estas múltiplas formas de busca de renovação espiritual refletem o cansaço em relação a técnica e consequentemente um empobrecimento da experiência, pois, para Benjamin (1986, p. 115), constituíam, não em uma renovação espiritual autêntica, mas numa galvanização, uma experiência de revestimento superficial, querendo fazer desta um refúgio, uma espécie de proteção dos males dos tempos. Para Benjamin (1986), com a modernidade a experiência se esmoreceu, tornou-se ínfima, pois, na complexidade desta sociedade o indivíduo vive cada vez mais ao seu jeito, atomizado em seus pequenos e próprios mundos, enquadrados em seus espaços reais e em nossos dias, imerso ao emaranhado de redes sociais e outros dispositivos da internet. Cada vez mais prevalece os comportamentos individualizados em numa sociedade, marcadamente caracterizada pela comunicação eletrônica instantânea que mesmo aproximando, tem poder de afastar as pessoas em um triste paradoxo.

Nesse processo de enfraquecimento da Erfahrung, segundo Benjamin (1986), o homem moderno passou a valorizar o romance e a informação jornalística em detrimento da memória e narração tradicional, da formação passada de geração em geração pelos mais velhos, que exigia no momento da narrativa, ouvir, ler e interpretar, internalizando a experiência. Trocou-se, segundo o frankfurtiano, o saber experiencial contido no passado, na narração, pela praticidade e utilidade do presente, o imediatismo da informação, descontextualizada e enfraquecida de sentidos. Nesta lógica, o caráter pragmático da sociedade administrada se impôs, onde o que não pode ser prático e utilizado deve ser descartado.

Com isso, assinala Benjamin (1986), perdemos o vínculo com o conto, com a narração, com o aprendizado oral herdado de nossos antepassados, com a história material que nos precede e ficamos à mercê de uma eterna novidade: nossos atos estão fadados e são reféns de um eterno hoje, com um prazo de validade preso ao momento do próprio acontecimento. Assim resta a pergunta desconcertante de Benjamim (1986, p. 115), ao indagar sobre "qual o valor de todo patrimônio cultural, se a experiência não se vincula a nós?” A pobreza de experiência leva a um ser humano desencantado, entristecido, com falta de ânimo e alegria, não pela falta de experiência, mas pelo não desejo de outras novas, pois se vê atropelado pelo excesso de informações e atividades, que não se convertem em experiências, impostas pelas 
fantasias da indústria do entretenimento presente nos meios de comunicação.

Assim, a existência cotidiana torna-se fria, insuportável devido a incapacidade de traduzir-se em experiência, pois tudo é efêmero, e a pressa, a ordem do dia, antes vista como imperfeição, agora é, nesta inversão de valores, o que determina tudo, pois o tempo é dinheiro, convertido como máxima a reger os atos e decisões das pessoas. Por isso, já afirmava Benjamin: "O homem de hoje não cultiva o que não pode ser abreviado" (BENJAMIN, 1986, p. 36).

Jarek (2014), reflete que a principal consequência deste estado de coisas é o rompimento do intercâmbio de experiências, o aniquilamento da memória do indivíduo, a perda do sentido de história, processo que tem reflexos profundos na formação de cada sujeito, implicando seus valores e concepção de mundo. Por isso, Benjamin (1986), ao testemunhar a perda da experiência do narrar, da memória, é regido pelo choque, pela experiência vivida do choque, pois toda experiência deste homem se vê diante da impossibilidade de ser autêntica.

Para Larossa (2002), o empobrecimento da experiência é reflexo da não compreensão de que o ser humano não se enquadra no tempo da máquina, na rapidez da técnica. Em concordância com Benjamim, defende que a experiência exige rompimento, força de interrupção, para que seja autêntica e possa efetivamente acontecer.

Por isso, Larossa afirmava que

a experiência, a possibilidade de que algo nos aconteça ou nos toque, requer um gesto de interrupção, um gesto que é quase impossível nos tempos que correm: requer parar para pensar, parar para olhar, parar para escutar, pensar mais devagar, olhar mais devagar, e escutar mais devagar; parar para sentir, sentir mais devagar, demorar-se nos detalhes, suspender a opinião, suspender o juízo, suspender a vontade, suspender o automatismo da ação, cultivar a atenção e a delicadeza, abrir os olhos e os ouvidos, falar sobre o que nos acontece, aprender a lentidão, escutar aos outros, cultivar a arte do encontro, calar muito, ter paciência e dar-se tempo e espaço (LARROSA, 2002, p. 24).

Esta interrupção aludida por Larrosa, de alguma forma constituiria em um momento de experiência ao se contrapor aos diversos mecanismos, instrumentos e constructos que sabotam ou mesmo ofuscam e negam o sentido de experiência na vida humana, ao ter o poder de redimensionar os nossos sentidos, aguçar a sensibilidade ao criar abertura para a intensidade do momento vivido.

Em Adorno, experiência é "a continuidade da consciência em que perdura o ainda não 
existente e em que o exercício e a associação fundamentam uma tradição no indivíduo" (ADORNO, 2006, p. 12). A afirmação de Adorno permite uma conexão com o pensamento de Walter Benjamin, na relação experiência (Erfahrung) e vivência (Erlebnis). As abordagens de Adorno e Benjamin sobre experiência podem ser identificadas como uma crítica à sociedade capitalista administrada que assenta sua base na ideia linear de progresso e no aqui e agora. Uma sociedade profundamente imediatista, cuja ideia de tempo e amadurecimento é relegado ou mesmo negado, pois tudo é fest, um frenesi, fugaz e convertível em dinheiro e prazer, desvalorizando e empobrecendo o conceito de experiência. Daí emerge um ser humano desequilibrado, empobrecido, insensível, frio, calculista e guiado pelo mito do progresso contínuo da história (BENJAMIN, 1986).

Em Adorno a experiência estética poderá ser um remédio contra este mal que afeta a humanidade. Esta experiência estética ocupa lugar privilegiado no pensamento de Theodor Adorno, por se mostrar capaz de desvincular-se da lógica da racionalidade instrumental (ADORNO e HOKEHIEMER, 2006).

Adorno e Horkheimer (2006), defendem que em um determinando momento, a sociedade e o ser humano passaram a ser dominados e administrados pela técnica e por uma forma de pensar instrumental, onde se perdeu de vista e empobreceu os valores estéticos constitutivos do humano. Todas as esferas das relações sociais foram afetadas, sobretudo a cultura, imprescindível para construção e funcionamento da sociedade. A cultura, segundo estes pensadores, transformou-se em um fenômeno onde também predomina o cálculo econômico. Segue desta constatação, um questionamento importante que merece atenção no direcionamento desta questão:

\footnotetext{
Se como defendem, os autores [da Dialética do Esclarecimento], a vida passou a ser dominada e administrada por uma forma de pensar ligada a razão instrumental, a qual se perdeu as finalidades da própria vida humana, se inclusive a própria cultura transformou-se em um fenômeno onde predomina o econômico e não o artístico, como possibilitar ao sujeito uma espécie de fuga dessa dominação constante ou um espaço no qual ele possa resistir a ela [grifo nosso] (PETRY, 2015, p. 11).
}

A resposta de Adorno seria a experiência estética, como uma possibilidade encontrada pelo sujeito para buscar um refúgio, no sentido de resistência e libertação para o enfrentamento de uma sociedade que funciona a partir da lógica da dominação pela razão. A discussão sobre experiência estética em Adorno tem como referência a questão da obra de arte, vista pelo autor como "possibilidade de expressão do não idêntico" (ADORNO, 1982, p. 
206). A arte teria capacidade de contrapor-se a atitude reducionista da lógica e da razão, imperativos da razão instrumental, conferir a natureza um lugar e de dar voz às vozes silenciadas pela razão (DUARTE JUNIOR, 2001).

Segundo Adorno (1982), a arte recuperaria os "impulsos miméticos" reprimidos pela razão, dissolvendo as barreiras entre o sujeito e o objeto, criadas pela razão instrumental. Em suma, numa sociedade que se constituiu sobre a dominação da razão e da técnica, o sujeito acaba fazendo renuncias e enfraquecendo suas relações e experiências, sobretudo estéticas. Assim, para Adorno (1982), a arte autêntica se apresenta como um modelo de comportamento alternativo ao imposto pela sociedade administrada. Nesta perspectiva, Adorno (1982) defende que, por não ter a finalidade prática e não se "enquadrar" na concepção do "servir" utilitarista e pragmático, elevando-se do mundo empírico e de suas regulações, a arte oferece ao sujeito uma experiência estética e de liberdade. A obra de arte autêntica, que para Adorno (1982, p. 206), seria aquela que não está "sujeitada", que preservou sua autonomia e não se curvou as sujeições e funções de determinações externas e, por isso, alcançou sua autonomia, consegue desvincular-se das finalidades práticas características da racionalidade instrumental, passando a mover-se por necessidades internas.

Deste modo, para que haja uma verdadeira experiência estética, segundo Schaefer (2012), ao retomar esta questão no pensamento adorniano, é fundamental que o seu conteúdo de verdade se revele por meio de uma reflexão filosófica, portanto, de forma não imediatista ou unicamente emocional, pois, "a genuína experiência estética deve tornar-se filosofia ou então não existe" (ADORNO, 1982, p. 202). Porém, Adorno não concebe a experiência estética como um ato ou sentimento somente ligado a obra de arte, restrito na sua concepção ou conceito. A experiência estética supõe emoção, razão e reflexão muito além da obra de arte (ADORNO, 1982).

O termo estético ou estética, tem sua origem em estesia que quer dizer sensibilidade, e é o oposto de anestesia. Aesthesis é a palavras grega que designa percepção, sensação, e podemos compreender as experiências estéticas como todas aquelas que envolvem nossos sentidos, percepções e emoções. A experiência estética é "uma condição e exigência do humano, independente do que a arte outorgada pode representar para os processos e meios dos quais nos humanizamos" (VAZQUEZ, 1999, p. 12).

A experiência estética é aquela que sensibiliza, que emociona, não tem relação necessariamente com o belo, com a contemplação de uma obra de arte, com um estado de 
transe que supostamente traz inspiração para o artista executar sua obra. A experiência estética funda a possibilidade de percepção e compreensão de que, na estrutura humana, pode haver uma integração entre o pensar e o sentir, ou dito com outras palavras, a razão e a sensibilidade não se excluem e menos ainda não se diferem em absoluto e mesmo na oposição, permanecem interdependentes (ADORNO, 1982, p. 364).

Enfim, a experiência estética resgata a essência, a plenitude do humano em nós na medida em que, pela sensibilidade, nos conecta com a realidade. Ou ainda, considerando as palavras de Pucci (2001, p. 2001), “a experiência estética oferece aos nossos sentidos uma dimensão de conhecimento e ao nosso entendimento uma dimensão de sensibilidade". Por isso, a recuperação ou fortalecimento da experiência estética, bem como do próprio sentido de experiência, postulado por Adorno e Benjamin, apresentam-se como um contraponto à lógica da razão instrumental e da indústria cultural por favorecer a formação dos sentidos, aguçar o pensamento criativo, favorecer a admiração, provocar em nós o estranhamento, criar possibilidades de pensar a realidade de inúmeras formas, favorecendo a formação humana, contribuindo para o entrelaçamento do sentir, pensar e agir.

Adorno (1982) e Benjamin (1986) não desconsideravam o valor da razão e da técnica, mas defendiam a necessidade de criticar a absolutização das mesmas e seus desdobramentos que desumanizam, reprimem, desvirtuam as potencialidades do ser humano e separam aquilo que precisa estar unido: razão e sensibilidade. Assim, o sentido de experiência e a experiência estética podem servir para educar nossa sensibilidade, nosso pensamento, ampliando a forma de compreender a realidade e qualificando nosso agir no mundo.

As críticas que Adorno faz à absolutização da razão e da técnica nos levam a pensar: seria possível falar em uma racionalidade estética? A reflexão sobre a racionalidade no pensamento adorniano é construída a partir de uma crítica que o pensador faz àquela razão erguida sob a inspiração iluminista.

$\mathrm{Na}$ visão de Adorno, a ideia iluminista de emancipação humana, por meio da razão para sair da condição de menoridade, acabou se convertendo no domínio racional. Ao se elevar, a razão se sobrepôs aos mitos e crendices, realizou o desencantamento da realidade, mas acabou impondo um saber racional com base no calculável, prático, seguro, exato, tornando-se instrumentalizada (ADORNO E HOKHEINER, 2006).

O advento do domínio da razão tornou-a incontrolável, violenta e repressiva, onde tudo tende a ser tratado como objeto, coisa manipulável, gerando a alienação, matematização, 
a coisificação sob a égide da racionalização e tudo. A razão voltou-se contra o próprio homem, excluindo o pensamento divergente, impondo a reificação do processo técnico (ADORNO E HOKHEINER, 2006).

A vitória da razão significou o controle, a normatização métrica e paranoica da dominação em todas as relações e o contrário tende a ser eliminado, desqualificado, porque não haveria, na concepção do império da razão, nada fora da racionalidade. Dito de outra maneira, na construção do ser racional, tudo tem que ser conformado, apaziguado, a pulsão emocional mutilada com o banimento dos vestígios humanos para que o lógico prevaleça e assim, os sentidos possam ser controlados ou permaneça no compasso ritmado da razão instrumental.

Adorno identifica este processo de domínio instaurado da razão na indústria cultural que racionalmente cria produtos simbólicos que perpetuam sutilmente a lógica do controle. Seus produtos simbólicos, segundo o autor, é a garantia da sociedade administrada dominada pela razão instrumental, pois, os produtos de baixa qualidade que disponibiliza estão a serviço da desinformação para anestesiar e impossibilitar um pensamento crítico capaz de desvendar a realidade, protegendo e mantendo a ordem social (ADORNO, 2012).

O resultado desta razão instrumental e da indústria cultural é a semicultura, uma cultura ausente de elementos que permita ao indivíduo interpretar o real, garantindo ao “consumidor cultural” por meio dos meios de comunicação e de várias instituições, como a própria escola, um conteúdo captado a partir de uma verdade ilusória, filtrada do real. Tudo é controlado pela razão e pela indústria cultural, determinando e limitando a experiência da vida de cada um, atrofiando a imaginação criativa do ser humano (ADORNO, 2012).

Mas a reflexão adorniana não só permite uma visão crítica do que se tornou a razão iluminista e do que ela se constituiu em nossos dias. Seu pensamento abre perspectivas para a possibilidade de outra racionalidade que não àquela da sociedade que emergiu do nascimento do capitalismo e em nosso tempo da autoafirmação do pensamento neoliberal.

Adorno nos permite pensar na estética da razão ou na racionalidade estética. Esta racionalidade seria desvinculada de um fim pragmático. Uma racionalidade pautada na experiência estética da razão como contraponto à lógica da razão instrumental e dos domínios da indústria cultual. Esta racionalidade estética seria o ponto de equilíbrio entre o sensorial e a razão (ADORNO, 1982).

Se na consolidação da razão instrumental a supremacia da razão fez suprimir o 
sentimento, o desejo e a emoção, provocando a cisão do indivíduo em sua corporeidade, a racionalidade estética, na perspectiva adorniana, promoveria o resgate do valor dos sentimentos, do afeto, da sensibilidade procurando integrar, por meio da experiência estética, a razão, o corpo e alma, racionalidade e corporeidade. Nas palavras de Adorno (1982, p. 69), "rememorar a natureza no sujeito que a racionalidade reprimiu".

A concepção de uma experiência estética em Adorno é bem demonstrada nas palavras de Nadja Hermann ao salientar que,

a experiência estética é compreendida na medida em que evidencia o ser humano em seu todo razão e emoção, ou seja, permitir este a sentir-se em seu todo, $[\ldots]$ não centrado apenas no sensível ou no racional como forma metafísica de pensar, pois a experiência estética possibilita o conhecimento daquilo que é excluído pela lógica do conceito, criando novas compreensões de mundo (HERMANN, 2005, p. 78).

Em Adorno (1982), a racionalidade estética é portadora da possibilidade de compreensão da estrutura humana, como unificadora da razão e sensibilidade, que embora, carreguem estranhamentos, são permanentemente interdependentes e esta não é apenas emoção, mas também processo de reflexão, de conhecimento e formação. Em conformidade com as ideias de Adorno, Duarte Junior, defende que "o inteligível deve caminhar ao lado do sensível, o conhecer em sintonia com o sentir, por conseguinte, mesclam-se lógica e sensibilidade, razão e sentimento, conceito e estesia, num caldeirão de ideias, novas percepções, novos olhares sobre o mundo e a vida". (2001, p.169)

\section{Fundamentos da experiência e da racionalidade estética na profissão docente}

Diante das reflexões construídas é certo dizer que um dos grandes desafios do trabalho docente é o enfrentamento da racionalidade neoliberal e suas consequências, pois, essa é portadora de mecanismos reforçadores de uma sociedade desumanizada, danificada e que empobrece o sentido de experiência e a estética na vida humana.

Neste contexto, tomar o trabalho docente como lugar potencial da experiência estética, supõe redescobrir o verdadeiro sentido de uma prática, disposta a romper com o processo de padronização e fragmentação da experiência formativa, conectada a um redescobrir do encantamento e da força de cada experiência de encontro entre professor e aluno, muito além dos conteúdos a serem ensinados e metas a serem cumpridas. Assim, o trabalho docente, 
exige um reinventar-se a cada dia, pois, como ficou demonstrado acima, o cotidiano escolar pode representar experiências de alegria, encorajamento, esperança, mas muitas vezes é marcado pela tristeza, desencorajamento, ilusão e o encarceramento do trabalho docentes que acabam sendo reproduzidas na sala de aula (RAMOS DE OLIVEIRA, 2007).

Conceber o trabalho docente a partir de uma racionalidade estética exige uma concepção de educação que resgate a força do docente como sujeito capaz de provocar o sentimento de autonomia, de ser educador do afeto, do sentimento, da busca do conhecimento como forma de compreender e transformar a realidade e ainda, recuperar a perspectiva ética e estética do ensinar. Tais perspectivas podem se constituir em experiências de educação inovadora, força, energia vital e possibilidade de resistência e empoderamento no cotidiano escolar (PAGNI, 2007).

A recuperação e tonificação do trabalho docente a partir da racionalidade estética pode representar uma oposição e resistência a sociedade neoliberal, sobretudo se caminhar no sentido contrário a de uma formação restrita à racionalidade técnica e aos ditames da indústria cultural, incapazes de proporcionar condições para uma autorreflexão crítica da semiformação (Halbbildung) a partir de uma formação em todos os sentidos (Bildung) que, na perspectiva de Benjamin (1987) e Adorno (1996), permite a reconstrução da humanidade a partir da rememoração e elaboração do passado, da consciência sobre a constituição da realidade, convertendo-se numa luta contra a padronização e a fragmentação da experiência formativa e do distanciamento entre o sentir, pensar e agir.

O trabalho docente se vê fortalecido quando é capaz de buscar a união do pensar, que se apropria da informação e a transforma em conhecimento por meio da reflexão e produção do saberes nas diversas disciplinas, do agir, que envolve todas as situações práticas, sejam elas das atividades e burocracias que permeiam os "afazeres" escolares ou mesmo o engajamento em uma ação política ou profissional, com o sentir, que envolve a sensibilidade, a beleza, o afeto, a emoção, que não elimina a razão e a técnica, mas a transcende, transvaloriza e a ressignifica a serviço do humano em sua construção.

A experiência estética supõe emoção, razão e reflexão, e assim, o trabalho docente, é um lugar privilegiado para promover condições objetivas de rompimento com a lógica da racionalidade neoliberal, pois é espaço propício de apropriação, por parte de professores e alunos, do legado cultural material e imaterial produzido pela humanidade de modo racional e sensível, que pode ser refletido, analisado e assimilado (ADORNO, 1982). 
Ao pensar o trabalho docente como contraposição à racionalidade neoliberal, ainda que a instituição escolar esteja imersa à mesma, Adorno (2006), dá indicação para pensar o processo educativo e a própria educação como processo de experiência e emancipação, visto como forma de resistência em relação às estruturas e mecanismos opressores da sociedade capitalista.

Conceber o trabalho docente na perspectiva da racionalidade estética é pensá-la do ponto de vista da produção de condições de emancipação que supõe a necessidade de construção da consciência verdadeira, que é capaz de pensar e criticar a realidade social, política e econômica a partir de elementos que a influenciam e fazem funcionar. Deste modo, neste particular uma consciência portadora de experiência, como afirmava Adorno:

Mas aquilo que caracteriza propriamente a consciência é o pensar em relação à realidade, ao conteúdo - a relação entre as formas e estruturas de pensamento do sujeito e aquilo que este não é. Este sentido mais profundo de consciência ou faculdade de pensar não é apenas o desenvolvimento lógico formal, mas ele corresponde literalmente à capacidade de fazer experiências. Eu diria que pensar é o mesmo que fazer experiências intelectuais. Nesta medida e nos termos que procuramos expor, a educação para a experiência é idêntica à educação para a emancipação (2006, p.151).

Neste sentido, a perspectiva da racionalidade estética acaba se apresentando como uma educação emancipatória, como "educação para a contradição e resistência” (ADORNO, 2006, p. 183), a partir de uma superação do reprodutivismo que a escola acaba por ser vítima em suas estruturas em relação a própria sociedade capitalista administrada, pois, ao reproduzir em si as estruturas sociais, políticas e econômicas vigentes, a educação escolar, repete e repercute o discurso programático e pragmático da sociedade capitalista.

Já a perspectiva da experiência estética no trabalho docente, permite pensar no âmbito da escola no estímulo da sensibilidade, do afeto, da percepção do corpo, na importância da razão e da cultura, não como valor de troca, mercadoria posta à venda, mediadora do sucesso ou insucesso, mas capaz de humanizar, fazer emergir um ser humano pleno e não apenas "peça", escravo submisso resignado ou conformado em ser produtor de mais-valia, como se este fosse o destino, utilidade e missão da escola e processos educativos (PAGNI, 2007).

A reflexão sobre a experiência estética no trabalho docente, por analogia, a partir das contribuições de Duarte Junior (2001), provoca-nos a pensar na necessidade de uma educação que se ocupe com o refinamento dos nossos sentidos, da escola ser um espaço não apenas do conhecimento intelectivo ou técnico, mas também de um saber sensível, uma escola que 
recupere o verdadeiro sentido de experiência. Essa compreensão revela uma concepção de educação como um processo formativo do humano que colabora no desenvolvimento dos sentidos e significados fundamentais para potencialização de uma sensibilidade que permita uma percepção mais apurada do mundo, sendo essa sensibilidade estimulada por meio de um processo que o próprio sujeito estabelece nas suas relações e que o faz desenvolver seus sentidos.

Deste modo, ao partir da experiência estética, o trabalho docente pode ser compreendido como educação das habilidades e sensibilidades humanas. Como contraposição às influências de uma razão instrumentalizadora que empobreceu a própria razão, impõe-se a necessidade de uma racionalidade estética, que na percepção de Olgária Matos (1993), emerge de uma experiência estética e ainda, segundo a autora, no pensamento adorniano, esta experiência acaba sendo um contraponto à lógica de uma razão instrumental e da indústria cultural, pois, pela sua força e essência, gera um equilíbrio entre os fatores racionais e sensoriais, integrando e harmonizando o sentir, o pensar e o agir.

A experiência estética redimensiona o trabalho docente ao inspirar um processo de ensino e aprendizagem que se move por um conhecimento que não é só racional, dado, pronto e acabado, que não pode simplesmente ser medido, reproduzido, mas que se faz, é lapidado pelas experiências cotidianas. $\mathrm{O}$ foco deste ensino e aprendizagem encontra na racionalidade estética sua realização, que liberta a imaginação e move diversas dimensões da existência que podem ser operadas na construção de um conhecimento que faça sentido tanto ao docente, quanto ao aluno, como diz Galzerani ao refletir sobre o pensamento de Matos (1993), "esta [a racionalidade estética] liberta o imaginário e a diversidade, em todas as suas dimensões (na linguagem escrita e falada, na expressão corporal, na produção de imagens, de símbolos). (GALZERANI, 2007, p. 8-9).

A experiência estética é carregada de uma força humanizadora e neste sentido é capaz de humanizar o trabalho docente em busca da construção de uma ciência a serviço do ser humano e não ao contrário, entendendo essa humanização como capacidade de ser sensível ao outro em suas expressões e manifestações. Essa sensibilidade, que traz à tona a experiência estética, atravessa as experiências cotidianas de cada docente e emerge de encontros que são vividos todos os dias, tornando cada tempo e espaço de ensino e aprendizagem, tempo e espaço de produção de sentido, onde o processo de construção do conhecimento é sempre mobilizado por experiências que tocam, atravessam e permanecem toda vez que afetamos e 
somos afetados, reinventando novas formas de percepção e expressão, portanto, tornando a docência, por excelência um lugar de experiência, sobretudo se movido pela dimensão estética.

A reflexão sobre o trabalho docente na perspectiva da experiência estética, como forma de entrelaçamento do sentir, pensar e agir sugere uma nova consciência e concepção da práxis do professor em sala de aula. Segundo Pucci (2001), a prática docente deveria ser movida pela "Bildung", formação em sua integridade, superando a habilitação apenas técnica, centrada na razão, no fazer e no domínio de informações específicas e didáticas.

A experiência estética se apresenta como possibilidade de um conhecimento por meio dos sentidos que nos afeta em nossa capacidade de perceber por este modo o sensível, abrindo o caminho para pensar a prática docente para além do aspecto inteligível, do conhecer, como forma de experiência do sensível, da Aesthesis, ou poder de perceber o mundo para além da teorização racional. Trata-se de uma experiência que amplia o âmbito do conhecimento, estendendo o olhar de uma racionalidade inteligível do conhecer, pensante, para envolver todo o corpo enquanto constituinte da aprendizagem.

Ao pensar o trabalho docente a partir da experiência, de modo especial, marcada pelo sentido estético, esta prática se vê fortalecida pela experiência do sensível, com capacidade de provocar uma interrupção, provocar choques (BENJAMIN, 1986), tem o poder de desacomodar, desalojar certezas, quebrar estereótipos e paradigmas, e refletir sobre experiências docentes capazes de inovar o fazer pedagógico, abrindo possibilidade de aulas que consideram a vida humana e a necessidade de se humanizar. Nesta linha de entendimento, não se trata de abolir as metodologias e estratégias de ensino, mas da sua potencialização a partir de um olhar docente cujas práticas refletem a concepção do aluno a partir de sua humanização, de um ser em construção que vai além do pensar e agir (VAZQUEZ, 1999).

Tomando como referência este olhar estético, o trabalho docente, ao internalizar esta experiência pode contribuir com todos os sujeitos do ensino e aprendizagem, sobretudo se for pautado em um saber lógico interligado com o saber sensível, capaz de desencadear experiências estéticas importantes no desenvolvimento da sensibilidade e da percepção humana na hora do conhecer. Desenvolve-se assim, uma prática que vai além do papel de transmitir o conhecimento, criando um ambiente onde este conhecimento passa a estar interligado a experiências culturais, existenciais e artísticas, portanto, estéticas, que desencadeiam um ensino e aprendizagem que recupera o sentir nas experiências entre 
professores e alunos, valorizando a humanidade destes, em um encontro que acontece de modo afetuoso, sensível na sala de aula, muito antes da questão racional e que cria uma motivação para o aprender, o pensar e o agir.

Para Duarte Junior, "o mundo antes de ser tomado como matéria inteligível, surge a nós como objeto do sensível" (2001, p. 13). Desta forma, pode-se inferir que o sentir tem a força de mover o pensar e o agir, e que a experiência estética no trabalho docente constitui-se na sua própria essência, como extensão de uma dimensão da educação, parte integrante e fundamental no processo de formação tanto do docente, quanto do aluno, e que é fundamental no processo de humanização que compõe a própria dimensão cultural do homem.

Portanto, o trabalho docente imbuído de uma experiência estética reveste o ato de ensinar de leveza, não sem consistência, porque ela se move no campo do querer, do desejar, motiva o aprender e inspira uma educação e prática docente que sejam objeto de desejo, admiração, encantamento, amor, paixão, alegria e entusiasmo. A docência por meio da experiência estética, pode, assim, ser

um lugar privilegiado de experiência de transformação de si e do outro [...] Muito além de um lugar de lamentação e impossibilidades diárias, à docência pode ser um lugar mesmo de experiência estética, onde, talvez seja possível, não exatamente pensar em nossos limites e as forças que nos constrangem, mas as condições e possibilidades infinitas, imprevisíveis e indefinidas de nos transformarmos e de ser diferente do que somos (FISCHER, 2009, p. 94).

Por isso, o trabalho docente, a partir da experiência estética, pode ser um processo de desbarbarização, ao propor uma educação que resista a barbárie a partir da consciência do passado como reelaboração do desenvolvimento da consciência autônoma, do resgate da sensibilidade, da consciência do outro e do comprometimento com a construção de uma nova realidade, livre da alienação, capaz de autorreflexão sobre os processos de danificação do pensamento e da sensibilidade, revestida de uma educação contra o processo semiformativo (ADORNO, 2012).

Neste ponto, o conceito de Walter Benjamim (1986) precisa ser retomado. Seu pensamento nos lança diante do desafio de recuperar o sentido de experiência do docente em um mundo inflacionado de informações que não nos formam e que é incapaz de fazer experiências, pois, lembra o autor, a informação não é sinônimo de formação, o conhecimento está vinculado à técnica e a tecnologia universal, objetiva e impessoal, mas não se converte em experiências que tocam, atravessam e permanecem, ficando sempre exterior ao homem, é 
alcançado, mas também não é compreendido, constituído em sua pessoalidade.

Diante desta situação, a relação de distanciamento entre sentir, pensar e agir, entendido como vivência e experiência afetou o sentido do trabalho docente, reduzindo-o a um pragmatismo utilitário para preparar os indivíduos para o mercado de trabalho. $\mathrm{Na}$ perspectiva de Benjamim (1987) o trabalho docente tornou-se utilitário decretando o fim da experiência, o tempo e as faculdades humanas se curvaram a práticas de endeusamento da técnica e do saber racional, e neste movimento, se a técnica do mundo moderno decretou o fim da experiência, a pretensa eficiência e domínio de técnicas pedagógicas de ensino para uma educação utilitarista, não foram diferentes para decretar o fim da experiência na atividade educativa, evidenciando um silenciamento, emudecimento dos docentes e dos alunos, nas suas subjetividades ou nas relações entre si.

De certo modo, a experiência estética no trabalho docente também se apresenta como uma possibilidade de enfrentamento deste emudecimento, a partir do momento em que esta experiência convida ao diálogo, abre espaço para a narrativa, para o falar de si mesmo e escutar o outro, criando uma nova perspectiva na cultura e experiência docente em relação as suas práticas. Pode-se dizer, que neste aspecto, a experiência estética está carregada da possibilidade de pensar, no modo benjaminiano, a "história escovada a contrapelo" (BENJAMIN,1992), dito de outra maneira, a prática docente escovada a contrapelo, numa disposição para uma nova prática, capaz de unir aquilo que nunca deveria ser separado, o sentir, o pensar e o agir, imprimindo no trabalho docente e nos processos educativos convivência, afeto, sentimento, alegria, energia, prazer pelo que se faz, permitindo uma educação dos sentidos como uma maneira de produzir uma “outra” perspectiva de educação.

\section{A estética da existência e o trabalho docente}

O pensamento sobre a estética da existência de Michel Foucault está contido em sua obra "História da sexualidade", no volume III, o cuidado de si, onde apresenta dois conceitos importantes, alinhados com o pensamento greco-romano e que permite, de certa maneira, uma aproximação com o resgate do sentido de experiência e racionalidade estética no trabalho docente. Estes conceitos são as técnicas de si e a estética da existência (REVEL, 2005).

Se em Walter Benjamin e Theodor Adorno encontramos argumentos para pensar na 
potencialização do trabalho docente, considerando o resgate do sentido de experiência e principalmente de uma experiência e racionalidade estética, é possível pensar, a partir de Foucault na criação, no trabalho docente de um estilo próprio, que transcende a realidade imposta, capaz de produzir a si mesmo, como artesão da beleza de sua vida e de sua obra, tornando seu trabalho uma extensão de sua existência, uma obra de arte (TIMM, 2006).

Deste modo, pode-se falar de uma aproximação entre o pensamento de Benjamin, Adorno e Foucault, em relação a sua reflexão sobre a estética da existência, ainda que sejam campos distintos, com a possibilidade de pensar no trabalho docente "um estilo para sua existência" (BIRMAN, 1997, p. 43), para além dos condicionamentos e restrições do seu ofício, impostos pela razão instrumental e estilo de vida segundo a sociedade neoliberal.

As técnicas de si ou cuidado de si eram práticas idealizadas pelos gregos e romanos com o objetivo de levar o indivíduo a realização, por ele mesmo, de exercícios, operações e atitudes em seu corpo, em sua alma e em seu pensamento. Essas técnicas visavam construir um estilo de vida, ou transformá-la em razão de um determinado fim para estabelecer o domínio de si, o conhecimento de si por si mesmo (FOUCAULT, 2004b).

Nestas técnicas, cada indivíduo buscava mudar o seu interior e alcançar sua singularidade, por meio da determinação de seus valores e de suas escolhas. Era o que os gregos chamavam de askesis, exercício e prática, para ocupar-se de si, epimeleia heautou (REVEL, 2005). Na visão de Foucault, não se trata de fugir da realidade numa atitude de renúncia, mas dar ao indivíduo uma preparação, capacidade de viver a realidade em que está inserido. A askesis consistia em um processo de subjetivação, uma força interior capaz de mover e modificar o ser em sua subjetividade, não como fuga, mas como força e resistência. Era uma ação que implicava o cuidado de si para se fortalecer e resistir a tudo que tende a enfraquecer o indivíduo, organizando a sua alma como forma de combater as forças sabotadoras da existência. Foucault descreve este caráter de fortalecimento das técnicas de si:

Mas ela tem uma função de luta. A prática de si é concebida como um combate permanente. Nãos e trata, simplesmente, de formar para o futuro um homem de valor. É preciso dar ao indivíduo as armas e a coragem que lhe permitirá lutar a vida inteira (FOUCAULT, 2004a, p. 124).

A estética da existência é o resultado das técnicas de si, na medida que esta permite a criação de um estilo próprio, visando a constituição de si mesmo como artesão da beleza de sua própria vida, transformando sua existência por meio de uma prática permanente a partir de critérios estéticos, éticos e políticos que definem o bem viver. A estética da existência como a 
racionalidade estética de Adorno, não é apartada da ética e está implicada na questão da prática da liberdade. A ética no sentido grego seria o ethos, o viver bem consigo mesmo e conduzir seus atos a partir de certos critérios (FOUCAULT, 2004b).

Na concepção grega de liberdade, o ser livre era aquele que não era escravo de ninguém e nem de si e nem dos seus apetites. $\mathrm{Na}$ ética do cuidado de si está a raiz das práticas da liberdade do sujeito, determinante de sua conduta, da ciência de seus atos e ações para si e para os outros. Para Foucault, a estética da existência é expressão da ética do cuidado de si, que implica suas ações em relação a si mesmo e ao outro. Segue desta afirmação que a estética da existência inspira uma vida inventiva, criativa, uma verdadeira obra de arte, capaz de transformar a si mesmo e o mundo (FOUCAULT, 2004a).

A contribuição de Foucault, sobretudo na estética da existência, nos leva a pensar na possibilidade de conceber o trabalho docente nesta perspectiva, como um lugar de experiência singular, com a criação de formas de subjetivação deste trabalho, exercícios e práticas de si que garantem a construção do estilo de cada professor, dotado de força interior capaz de resistir aos dispositivos da racionalidade instrumental da sociedade neoliberal, que tende a impor um modelo único de profissão do professor. A estética da existência tem a força de fixar a identidade individualizada do trabalho docente, transformando o seu trabalho em algo sublime, que transformam sua prática e sua obra (TIMM, 2006).

Deste modo, ao unir ética, estética e política como modos de construir a sua existência, o docente pode torna-se capaz de lidar com os conflitos e opostos de forças que abatem seu trabalho e que constituiria o processo de subjetivação de sua profissão sempre se fazendo e refazendo permanentemente. Por isso, o trabalho docente em uma dimensão de estética da existência está imbricado no sentido de arte, sensação, pulsão, prazer, desejo e reinvenção de si como força motora de seu trabalho (PAGINI, 2011).

Para Hermann (2005), o cuidado de si e a estética da existência foucaultiana sugere um sentido de experiência, como algo que constitui e permanece no individuo, não como algo fugaz, efêmero, mas como uma atitude crítica que põe à prova os limites que nos são impostos e que contribuem para tornar o que somos. Aqui podemos pensar na proximidade com o pensamento benjaminiano de experiência, pois, o docente no cuidado de si, pode criar um estilo de vida próprio que transcende a realidade e lhe confere força, mesmo nas adversidades de seu trabalho, tornando sua experiência algo que lhe toca e transforma. E conclui a autora acima, "é nas experiências dos limites e das contingências que nos tornamos o que somos e 
podemos desenvolver práticas de criação de nós mesmos" (2005, p. 19).

Pensar o cuidado de si, como um fundamento do trabalho docente pode conferir à sua existência um sentido estético que vai para além do pragmatismo que marca esta profissão. Neste sentido o próprio Foucault nos faz refletir sobre um conjunto de atitudes e exercícios que podem fortalecer o docente em si mesmo:

Existem os cuidados com o corpo, os regimes de saúde, os exercícios físicos sem excesso, a satisfação, tão medida quanto possível, das necessidades. Existem as meditações, as leituras, as anotações que se toma sobre livros ou conversações ouvidas, e que mais tarde serão relidas, a rememoração das verdades que já se sabe, mas de que convém apropriar-se ainda melhor. Em torno dos cuidados consigo toda uma atividade de palavra e de escrita se desenvolveu, na qual se ligam o trabalho para consigo e a comunicação para com outrem (FOUCAULT, 2004b, p. 56).

Cuidar de si é uma tomada de atitude, pois, "ocupar-se consigo não é pois, uma simples preparação momentânea para a vida; é uma forma de vida" (FOUCAULT, 2004b, p. 446). Esta afirmação diz muito diante do enfraquecimento do trabalho docente na racionalidade neoliberal e deve nos fazer pensar.

\section{Considerações finais}

Pensar os fundamentos do trabalho docente a partir de uma experiência e racionalidade estética constitui o esforço deste ensaio. Uma "outra" prática docente pode nascer e se fortalecer como opção radical à influência do processo de instrumentalização da razão na sociedade neoliberal.

Admitir o trabalho docente como construção artística nos remete ao sentido de fazer uma experiência estética por meio desta prática ou despertar a experiência por meio dela. Trata-se de uma experiência que na perspectiva estética é capaz de despertar a beleza e o entusiasmo e inspirar o encantamento do ofício de ensinar e aprender e inspirar uma "nova" prática docente no sentido estético do ato educativo que se prima pela racionalidade estética. O resgate de uma estética da existência na criação de um estilo próprio e pessoal, de um modo de viver inspirado em valores diferentes dos impostos pela sociedade neoliberal e sobretudo o cuidado de si, são essenciais no fortalecimento do trabalho docente.

A importância da atividade pedagógica, não reside essencialmente no produto final, não é o cumprir simplesmente uma meta, terminar alguma tarefa, numa ordem racional e 
lógica, mas o foco precisa estar no processo, na criação e no desencadear das atividades. Seja qual for a área do conhecimento, o objetivo maior do trabalho docente não é o cumprir simplesmente um currículo fechado, terminar um projeto imposto, ensinar o que está prescrito pelos técnicos, mas mobilizar o sentir, o agir e o pensar de alunos e docentes no processo de imaginação criativa da atividade educativa.

O trabalho docente ancorado na experiência estética se vê revestido de encantamento e de entusiasmo, desperta a paixão e o desejo de contemplação. Encantamento e entusiasmo são estados da experiência estética que tem poder de recuperar a força do docente em suas práticas escolares. Encantamento não é o sentido mágico espiritualista contra o qual reagiram os iluministas, mas consiste na sensação de deslumbramento, admiração, grande prazer que se tem como reação a alguma coisa que desperta alegria, beleza quando se vê, ouve, percebe e que não sai de sua memória, pois no sentido Benjaminiano e Larrosiano, toca, atravessa e permanece, mesmo quando essas experiências são dadas pela dor, perda ou pela tragédia.

Contudo, é preciso reconhecer que há limites na ação docente. Cada docente é antes de tudo um ser humano, carregado de paixões, força interior, mas também de fraquezas e limitações. Sua prática está sempre imersa em um contexto em que pesam questões políticas, econômicas e sociais que incidem e não raramente, enfraquecem o seu fazer pedagógico. A prática docente nunca é um ato isolado, onde o docente deva ser visto como asceta, um herói ou um mártir. Mas antes, sua prática se fortalece no reconhecimento coletivo, nos processos de encontro e reencontro, na convivência social com os seus pares, onde se avaliam as experiências éticas e estéticas na formação e no trabalho docente.

A experiência estética é uma possibilidade de recuperar a beleza do ensinar e aprender na sala de aula, mesmo nos momentos onde a razão instrumental tende a se impor. Como foi dito, a palavra estética deriva de Asthesis, faculdade do sentir, tem a ver com todas as nossas habilidades de sentir, perceber o mundo que nos rodeia pela sensibilidade. Na experiência estética, nossas faculdades de sensação e percepção são revitalizadas de maneira significativa. Esta experiência estética expressa a beleza, produz o sentido de prazer e faz com que o aluno queira seguir por este caminho. Toda vez que temos uma experiência estética, vivenciamos um momento de encantamento que produz entusiasmo.

A experiência estética no trabalho docente ao resgatar a estética da razão pode ser um choque na educação bancária, reflexo da racionalidade técnica, que ainda insiste em se fazer presente no cotidiano escolar, atuando como um anestésico e configurando um trabalho 
docente que ainda julga a informação e apenas o racional como supremo valor em detrimento das experiências subjetivas.

Por isso defende-se a ideia de um trabalho docente fundamentado na experiência estética como forma de fortalecer o seu ofício, considerando a atividade educativa como arte e o docente como grande artesão da formação humana a partir do cuidado de si, por meio de práticas que rompem com um modelo estereotipado da racionalidade técnica. A dimensão do cuidado de si pode tornar-se decisiva na promoção de condições especiais que tonificam o trabalho docente ao possibilitar a criação das experiências estéticas possíveis, exercitadas física, emocionalmente e intelectualmente no cotidiano escolar. Elas se expressam por meio de experiências de narrativas, expressões corporais, imagéticas, verbais, orais ou escritas, nos encontros e reencontros diários, nos diálogos e conversas informais, na aula expositiva ou no debate sobre um determinado tema, no ensino e na aprendizagem de algum conhecimento, no mais moderno uso de tecnologia e na mais simples técnica e recurso de ensino. Na sala de aula, ou na escola toda, a atividade docente pode ser uma rede de experiências estéticas que nos tocam permanentemente, porque são movidas por narrativas e experiências vividas e revividas na leitura de textos, poemas, músicas, versos que nos afetam e atravessam, porque são plenas de sentidos, sensações e sentimentos para os sujeitos envolvidos nesses processos.

A prática docente como arte e recuperação do sentido de experiência, sobretudo da experiência estética, e da racionalidade estética, confere ao ato de ensinar e aprender uma esteticidade capaz de revolucionar o trabalho docente, ainda que haja adversidades, ao mesmo tempo em que materializa o sentido maior da educação, a formação (Bildung) humana em todas as suas dimensões.

\section{Referências bibliográficas}

ADORNO, Theodor. Teoria estética. Trad Artur Morão. Lisboa: Edições 70. 1982.

ADORNO, Theodor. Teoria da semicultura. In: Educação \& Sociedade: revista quadrimestral de ciência da educação, ano XVII, n. 56, Campinas: Editora Papirus,dez./1996, p. 388-411.

ADORNO, Theodor. Educação e Emancipação. Trad. Wolfgang Leo Maar. 4. Ed. São Paulo: Paz e Terra, 2006.

ADORNO, Theodor. Indústria cultural e sociedade. São Paulo: Paz e Terra, 2012

ADORNO, Theodor; HORKHEIMER, Max. Dialética do esclarecimento: fragmentos filosóficos. Tradução de Guido Antônio de Almeida. Rio de Janeiro: Jorge Zahar Ed., 2006.

BENJAMIN, Walter. Teses sobre a filosofia da história. In: Sobre Arte, Técnica, Magia e

Revista Devir Educação, Lavras, vol.4, n.2, p.343-372 jul./dez., 2020. 
Política. Trad. Maria Luz Moita. Lisboa: Relógio D`Água, 1992

BENJAMIN, Walter. Experiência e pobreza. In: Magia e Técnica, Arte e Política. Trad. Paulo Sérgio Rouanet. São Paulo: Brasiliense, 1986.

BENJAMIN, Walter. A obra de arte na era de sua reprodutibilidade técnica. Magia e Técnica, Arte e Política. São Paulo: Brasiliense, 1987. p. 213-248.

BIRMAN, Joel. Entre Cuidado e Saber de Si - Sobre Foucault e a Psicanálise. 2.ed. Rio de Janeiro: Editora Relume Dumará, 2004.

BUCK-MORSS, Susan. Estética e anestética: o "ensaio sobre a obra de arte" de Walter Benjamin reconsiderado. Travessia, n. 33, UFSC, Santa Catarina, p. 11-41, 1996.

DUARTE JUNIOR, João Francisco. Fundamentos estéticos da educação. $6^{a}$ ed. Campinas: Papirus, 2001.

FISCHER, Rosa Maria Bueno. Docência, cinema e televisão: questões sobrea formação ética e estética. Revista Brasileira da Educação, v. 14, n. 40, p. 93-102, jan./abr. 2009.

FOUCAULT, Michel. A ética do cuidado de si como prática da liberdade. In: FOUCAULT, Michel. Ditos \& Escritos: Ética, sexualidade e política. Vol. V. São Paulo: Forense Universitária, 2004, p. 264-287.

FOUCAULT, Michel. Hermenêutica do Sujeito. São Paulo: Martins Fontes, 2004. Valencia: Pretextos, 2004.

GALZERANI, Maria Carolina Bovério . O lugar das memórias na produção dos saberes escolares. Encontro Regional de História. São Paulo: ANPUH (SP), 2007.

HERMANN, Nadja Prestes. Ética e estética: a relação quase esquecida. Porto Alegre: EDIPUCRS, 2005, 119 p. Disponível em: < https://www.scielo.br/pdf/es/v29n102/a0229102.pdf> Acesso em: 05 de maio 2020.

JAREK, Márcio. Por uma outra experiência na Educação. In: MARTINS, Francisco Marcos. Filosofia da Educação: ensaio sobre autores clássicos. EDUFUSCAR. São Carlos 2014.

KONDER, Leandro. Walter Benjamin: o marxismo da melancolia. Rio de Janeiro: Campus, 1998.

LARROSA, Jorge. Notas sobre a experiência e o saber da experiência. Revista Brasileira de Educação. Nº 19. Jan-Abr 2002. Disponível em:

<http://www.anped.org.br/rbe/rbedigital/RBDE19/RBDE1904JORGELARROSABONDIA.pdf.>. Acesso em: 3 de maio de 2020.

MATOS, Olgária. O Iluminismo visionário: Benjamin, leitor de Descartes e Kant. São Paulo: Brasiliense, 1993.

MONLEVADE, João Antônio Cabral; SILVA, Maria Abádia. Quem manda na educação do Brasil? Brasília, Idea, 2000.

PAGNI, Pedro Ângelo. A dimensão estética da atividade pedagógica e da experiência educativa no pensamento de Adorno. 2007. Disponível em:

<www.ufsm.br/gpforma/1senafe/bibliocon/adimensao.rtf>. Acesso em: 20 de abril 2020.

PAGNI, Pedro Ângelo. O cuidado de si em Foucault e as suas possibilidades na educação: algumas considerações. Disponível em: 
https://www.marilia.unesp.br/Home/Publicacoes/foucault_book.pdf> Acesso em: 5 de maio 2020.

PETRY, Franciele Bete. Experiência Estética em Theodor W. Adorno: Diálogos com a Educação. Impulso, Piracicaba. 7-17, jan.-abr. 2015. Disponível em: <http://dx.doi.org/10.15600/2236-9767/impulso.v25n62p7-17>. Acesso em: 04 de maio 2020.

PUCCI, Bruno. Educação, pensamento e sensibilidade. In: ZUIN, A. A. Soares; PUCCI, Bruno. (orgs). Teoria Crítica, estética e educação. São Paulo: Autores Associados, 2001.

PUCCI, Bruno; RAMOS DE OLIVEIRA, Newton. O enfraquecimento da experiência na sala de aula. Pró-Posições: UNICAMP, v. 18, p. 41-49, 2007. Disponível em: < https://periodicos.sbu.unicamp.br/ojs/index.php/proposic/article/view/8643572>. Acesso em: 02 de maio de 2020.

RAMOS-DE-OLIVEIRA, Newton. Do ato de ensinar em uma sociedade administrada. In: Indústria Cultural e Educação. Campinas, SP: Cadernos Cedes 54, 2002. p. 19-27.

REVEL, Judith. Michel Foucault. Conceitos essenciais. São Paulo: Clara Luz, 2005.

SCHAEFER, Sérgio. A teoria estética em Adorno. Tese de doutorado. Universidade Federal do Rio Grande do Sul. Instituto de Letras, Programa de Pós-Graduação em Letras. Porto Alegre, 2012.

TIMM, Edgar Zanini. O bem-estar na docência: dimensionando o cuidado de si. Porto Alegre: PUCRS, 2006. Tese de doutoramento.

VAZQUEZ, Adolfo Sanchez. Ética e Estética. Rio de Janeiro: Civilização Brasileira: 1999.

Recebido em 30/07/2020

Aprovado em: 09/09/2020 